\title{
Pervasive skills development for aspirant chartered accountants: Academic versus training programmes
}

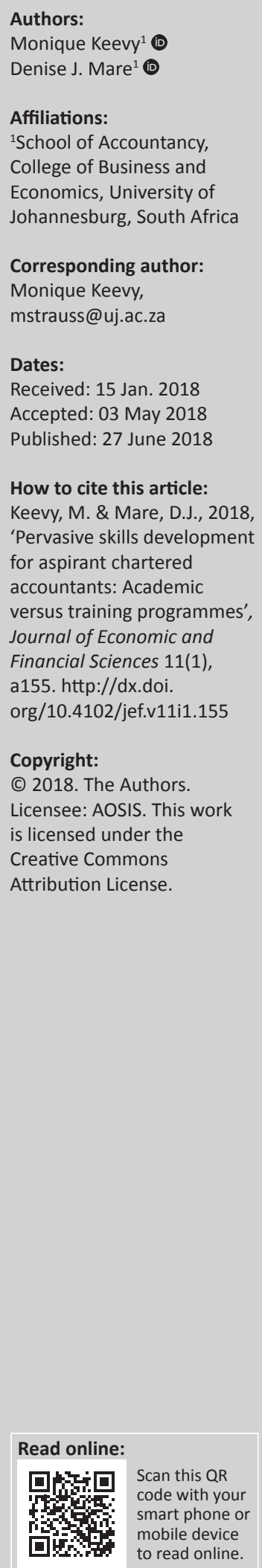

\begin{abstract}
Changes in the business environment have challenged both the technical and pervasive competencies of aspirant professional accountants (or chartered accountants [CAs]). Accounting bodies have responded to this need by adopting competency-based qualification models. Likewise, in 2008, the South African Institute of Chartered Accountants developed a Competency Framework where aspirant CAs are now assessed on both technical and pervasive skills en route to qualifying as CAs, the latter being the focus of this article. The article aims to ascertain the views of aspirant CAs on the effectiveness of academic and training programmes en route to qualifying as a CA. It also seeks additional vehicles to improve the delivery of pervasive skills during qualification. This research uses empirical data in the form of a questionnaire with both open and closed response options. The study reveals that both programmes are critical to the success of qualifying as a CA, but further emphasis is required in developing pervasive skills for both programmes. The findings also demonstrate the importance of using methods such as cases, mentorship programmes and internship programmes in equipping candidates with pervasive skills. The use of separate modules to develop pervasive skills during both programmes was also strongly supported by the majority of aspirant CAs.
\end{abstract}

\section{Introduction}

This article reports on a study of the perceptions of aspirant chartered accountants (CAs) on the effectiveness of academic and training programmes in transferring pervasive skills en route to qualifying as a CA. The interest in the topic arose given the conflicting views on where the responsibility lies for developing pervasive skills (Barac \& Du Plessis 2014; International Federation of Accountants [IFAC] 2015; Lines \& Gammie 2004; Strauss-Keevy 2014), and the requirement of universities and training programmes, as part of their professional accreditation to report to membership bodies, on how they incorporated pervasive skills into their curriculum (Gammie, Cargill \& Hamilton 2010; Jackling \& De Lange 2009; SAICA 2009).

Accounting education has been under scrutiny for the past few decades, given the changes in the accounting profession in terms of proliferating regulations, rapid advancements in technology, globalisation and corporate failures (Albrecht \& Sack 2000). Furthermore, the common theme emerging from the literature is that accounting graduates should develop not only technical acumen but also pervasive skills (Albrecht \& Sack 2000; Barac 2009; Fouché \& Visser 2008; Kermis \& Kermis 2010; Mohamed \& Lashine 2003), which are also referred to as soft skills, generic skills, non-technical skills and employability skills in the literature (Crebert et al. 2004; De Villiers 2010; Jackling \& De Lange 2009). Various accounting bodies have responded to these challenges. In particular, in 2008, the South African Institute of Chartered Accountants (SAICA) introduced a Competency Framework (SAICA 2009).

The Competency Framework was developed to ensure that the CA designation remains relevant to the changing business arena (SAICA 2015a; Steenkamp 2012) and also meets the requirements of the IFAC (2015). This framework requires SAICA-accredited universities and training programmes to ensure that each pervasive skill is addressed in their programmes and that evidence of this is provided to SAICA $(2009,2017 \mathrm{c})$. The training programmes serve as the practical training ground for aspirant CAs and are classified as large, medium or small firms, commerce and industry, or the public sector.

SAICA changed its previous final qualifying examination to a competency-based assessment, now referred to as the Assessment of Professional Competence (APC) (SAICA 2015b). The APC assesses both technical and pervasive skills, as conveyed in SAICA's objective of the APC being the 'assessment of professional competence developed during the academic, professional and 
training programmes to the extent possible in a simulation' (SAICA 2013:11). Therefore, at the time of sitting for the APC, aspirant CAs would have already completed a minimum of a 4-year academic programme and 2 years of the required minimum 3-year training programme (SAICA 2016a).

Various international and local studies have investigated teaching methods during the academic programme (Adler \& Milne 1997; Ballantine \& McCourt Larres 2009; De Villiers \& Fouché 2015; Fouché \& Visser 2008; Keevy 2015, 2016a; Lines \& Gammie 2004; Mohamed \& Lashine 2003; Viviers 2016) and the training programme (Gammie et al. 2010; Lines \& Gammie 2004) that addressed pervasive skills. However, none of these studies were presented from the viewpoint of aspirant professional accountants en route to qualifying as CAs. Furthermore, De Lange, Jacking and Gut (2006:382) convey that a study examining student perceptions after completing their professional accreditation would be interesting to ascertain whether pervasive 'skills deficiency is a short-term or long-term perception of accounting graduates'. Therefore, this article makes the following specific contributions:

- Insight from aspirant professional accountants on which programmes they viewed had the biggest impact on their pervasive skill development en route to qualifying as CAs.

- Support for particular methods that can be used to develop pervasive skills.

- Contribution to the ongoing discussion on the practicalities and methods that can be employed by academics and training providers in modifying their curricula to aid in the development of pervasive skills.

The remainder of this article is organised as follows: the next section describes the literature review, followed by the 'Research method' and 'Empirical findings' sections. The conclusions, limitations and areas for future research are presented in the last section.

\section{Literature review}

The IFAC (2015) advocates that the demarcated routes for aspirant professional accountants to develop professional skills should be through both the academic and the training programmes and aptly states that 'learning and development through which aspiring professional accountants first develop competence leading to performing their role as professional accountant include general education, practical experience and assessment' (p. 11).

This is supported by various academics (Ballantine \& Mc Court Larres 2009; Bui \& Porter 2010; Gammie, Gammie \& Cargill 2002), who view that the academic and the training programmes have an equally important role in developing pervasive skills. However, De Villiers (2010) has conveyed that it may be impracticable to expect graduates completing their academic programme to possess all the required pervasive skills. Similarly, Kavanagh and Drennan (2008) suggest that training programmes should not assume that graduates possess all pervasive skills when entering the work environment. Furthermore, several academics also view that pervasive skills are best developed in the workplace (Jackling \& De Lange 2009; Lines \& Gammie 2004). In the words of Lines and Gammie (2004:124), 'the ability to perform any job is evidenced, ultimately, by doing it'. Furthermore, Atkins (1999) is of the opinion that graduates should add value to a company from day 1 , as companies cannot afford to pay the cost of training graduates in terms of pervasive skills. She concludes by stating that 'universities have to ensure that graduates can hit the ground running' (1999:274).

In its latest Handbook of International Education Pronouncements, the IFAC states that the academic programme lays the foundation for aspirant professional accountants, but the training programme serves a complementary role (IFAC 2015). SAICA (2017b) concurs that the academic and the training programmes have a joint responsibility in producing competent professional accountants by conveying that the:

education and training of professional accountants must provide a foundation of knowledge, skills and professional values that enable them to continue to learn and adapt to change throughout their professional lives. (n.p.)

Furthermore, the training programme should complement the academic programme by addressing both technical and pervasive skills (SAICA 2017b). Star and Hammer (2008) view that universities should respond to the needs of the profession by developing teaching initiatives to address these pervasive skills. Gammie et al. (2010) emphasise the importance of introducing the assessment of pervasive skills prior to the final qualifying examination; otherwise, aspirant professional accountants will not see the benefit of these skills.

Certain studies have indicated where individual pervasive skills are best addressed. For example, in Crebert et al.'s (2004) study, it was found that the pervasive skills most notably developed during the academic programme were communication, problem-solving, team work and critical thinking. Conversely, the pervasive skills pertaining to demonstrating leadership and entrepreneurial skills, assuming responsibility, making decisions and demonstrating high ethical values were more suitable to the workplace.

There is also a considerable amount of literature pertaining to the individual pervasive skills regarding ethical behaviour and professionalism. The IFAC (2006) advocates that learning ethics in the workplace is as important as learning ethics in an educational setting. Flemming (1996) asks universities and professional bodies if accountants are best suited to teach accounting ethics to students. The author adds that 'the responsibility for the ethical education of professional accountants cannot be placed solely, or even largely, on the universities' (Flemming 1996:25). Another study indicated that ethics education should be learnt during pre-qualifying programmes, that there should be a dedicated unit, and also 
it should be integrated with other units during the prequalifying programmes (Jackling et al. 2007). Some argue that academic providers do not have a responsibility to contribute towards the development of the ethical values of graduates (Smith 2003) given that they are ill equipped to properly teach ethics (Bampton \& Cowton 2002; Frank, Gradisher \& Ofobike 2010). Bampton and Cowton (2002) posit that ethics education should be integrated in the business curricula, while Barac and Du Plessis (2014) highlight the importance of the integration of ethical behaviour and professionalism into the final year academic modules such as taxation, management accounting, financial management and financial accounting.

In 2010, the New Zealand Institute of Chartered Accountants (NZICA) decreased its 4-year academic programme to a 3-year programme. From their study, Low, Samkin and Liu (2013) found that the majority of accounting graduates maintained that the number of years in a degree should not impact the development of pervasive skills. Furthermore, only a small minority (six) out of 50 accounting graduates were of the opinion that universities have a responsibility to provide pervasive skills to accounting students. Therefore, Low et al. (2013:31) concluded that there 'are areas for improvement in terms of soft skills development with the accounting education curriculum'.

From a South African perspective, Viviers (2016) claims that SAICA-accredited universities need to develop competencybased teaching methods that will develop pervasive skills. Hesketh (2011:1-2) agrees with this view by conveying that 'assessing the additional competencies in professional examinations will involve new assessment approaches', which will influence the way academic providers teach and assess their students. However, Strauss-Keevy (2014) found that academics view that the training programme develops pervasive skills more effectively than the academic programme given that academics are not equipped in this regard, and De Villiers (2010) stated that:

despite $[a n]$ already full degree programme and numerous other internal challenges, [the] faculty will need to find innovative ways to deliver on the demands of stakeholders if they wish to remain relevant and competitive. (p. 10)

On the contrary, Hesketh (2011) surmised that academics have a greater accountability to prepare aspirant CAs in developing pervasive skills that would be demonstrable in examinations such as the APC.

In another South African study, the heads of departments at SAICA-accredited universities were asked to reflect on where the pervasive skills are most effectively developed en route to qualifying. Their overriding view for 24 of the 25 pervasive skills listed in the Competency Framework was that the workplace had a bigger role to play than the undergraduate academic programme. However, the heads of departments concluded that there is a shared responsibility between the academic and the training programmes, but a higher degree of reliance should be placed on the training environment for developing the pervasive skills (Barac \& Du Plessis 2014).
From the literature set out above, there are different views on where the ultimate responsibility for developing pervasive skills lies. SAICA is however clear in its message that accredited universities and training programmes should ensure that each pervasive skill is addressed in their programmes and that evidence of this is provided to SAICA $(2009,2017 \mathrm{c})$. Therefore, this article set out to ascertain where aspirant CAs viewed the pervasive skills were most effectively developed en route to qualifying as a CA.

\section{Research method}

The aim of this study was to ascertain where pervasive skills are most effectively developed en route to qualifying as a CA. In order to explore candidates' views regarding the academic and the training programmes en route to qualifying, a research instrument in the form of a questionnaire was developed to elicit the necessary information. The development of the questionnaire was aided by the review of the relevant literature in terms of SAICA's qualification process and a study conducted by Strauss-Keevy (2014). Strauss-Keevy analysed academics' views on the vehicles that most effectively develop pervasive skills. However, this study was from the viewpoint of academics. Therefore, it was felt appropriate to develop an adapted questionnaire for the purpose of this research.

The questionnaire consisted of three sections of mostly closedended questions of a quantitative nature. Comment boxes comprising the qualitative aspects of the questionnaire were included at the end of each section allowing descriptive responses to enrich and expand on the research results. Data from these open-ended questions were analysed by one author and reviewed by the other author. Section 1 was designed to capture the views of aspirant CAs on the APC and whether pervasive skills are developed en route to qualifying. Section 2 attempted to elicit candidates' views on the effectiveness of various vehicles during the qualification process. Section 3 was concerned with aspirant CAs' views on whether separate courses should be offered to develop pervasive skills during the qualification process.

The questionnaires were pilot tested by a selected group of aspirant CAs. A data controller was used to set up an online website where the questionnaire could be answered and the data could be recorded. Ethical clearance was obtained to distribute the questionnaire to aspirant CAs from SAICA. The questionnaire, containing a dedicated uniform reference (URL), was sent via email to aspirant CAs. The participants were directed to a website and asked to complete the questionnaire by clicking on the URL. The data controller collated the completed questionnaires electronically.

\section{Population of the study}

The population for the empirical work included all aspirant CAs who wrote the first APC in November 2014. As this is the final assessment en route to qualifying as a CA, the aspirant CAs had already undergone the full scope of academic, training and professional development programmes. As they had first-hand knowledge on various 
aspects of the qualification programme, they were able to provide insight on the effectiveness of the academic and the training programmes (SAICA 2017a).

\section{Response rate}

In total, 2050 emails were dispatched, with a response rate of $66 \%$. Note that none of the questions in the questionnaire were compulsory and the participants could refrain from answering a particular section or question in a section.

\section{Empirical findings}

\section{Aspirant chartered accountants' views on the new qualifying examination}

The objective of this section in the questionnaire, as set out in Table 1, was to ascertain the aspirant CAs' views on the APC. A five-point Likert scale was used by aspirant CAs to rate the statements: 1 = don't agree at all, 2 = agree to a lesser extent, 3 = agree to a moderate extent, $4=$ agree to a large extent and 5 = agree completely.

It is evident from the first two questions in the table that the majority of aspirant CAs are familiar with the Competency Framework (47\%) as well as the specific pervasive skills as detailed in the Competency Framework (44\%), as they 'agreed completely' with these two statements.

A comment made by a respondent highlighted the change in the new qualifying examination:

'The APC required candidates to be constantly learning, to be aware of the economic environment in which they work in. The APC teaches you how to look at problems holistically and to develop links between the different competencies.' (Participant 3, medium firm)

This view was shared by another respondent who further noted a shortfall of the CA profession:

'The APC exam embodies a revolutionary chartered accountant profession, moving away from the traditional bean counter, to a full rounded strategic thinker. However, in my opinion, one of the greatest shortfalls of the profession is developing business acumen, such as innovation, creativity, marketing and basic business start-up skills. Chartered accountants are not encouraged or afforded the skills to become entrepreneurs in the small to medium business sector.' (Participant 275, public sector)

The vast majority of aspirant CAs agreed 'to a large extent' or 'agreed completely' (81\%) that they developed the pervasive skills in preparation for the APC in 2014. Therefore, from the viewpoint of aspirant CAs, pervasive skills are developed en route to qualifying as a CA. Consequently, the CA qualification programme is aligned to the expectations of the profession and the objective of SAICA (2017b). Therefore, the follow-up question on 'which vehicles most effectively develop pervasive skills?' as set out in the 'aspirant chartered accountants' views on the vehicles that develop pervasive skills' section could be asked.

\section{Inferential statistics on aspirant chartered accountants' views on the new qualifying examination}

Further analysis of the data was conducted by using oneway analysis of variance (ANOVA) test (Pallant 2011) to establish significant variances within the aspirant CA group. A comparison was performed on the different training programme classifications, namely, large, medium or small firms, the public sector and commerce and industry (see Table 2).

Significance in $p$-value of the first two questions was evident with $p$-values of less than 0.05 . Although the first question was significant, statistically no differences within the CA group could be identified. For the second question ( $p=0.001)$, commerce and industry candidates indicated that they were the most familiar with the pervasive skills, whereas candidates from large firms indicated the least familiarity with the pervasive skills.

\section{Aspirant chartered accountants' views on the vehicles that develop pervasive skills}

In the second section of the questionnaire, the aspirant CAs were asked the following question: 'which vehicles most effectively develop pervasive skills?' The participants were asked to rank the effectiveness of the vehicles en route to qualifying as a CA. The ranking was from 1 (most effective) to 4 (least effective), and the condition was that participants could use each number only once. The results of the section

TABLE 1: Aspirant chartered accountants' views on the new qualifying examination.

\begin{tabular}{|c|c|c|c|c|c|c|c|}
\hline Views on new qualifying examination & 1 & 2 & 3 & 4 & 5 & $n$ & $M$ \\
\hline 1. I am familiar with the content of SAICA's Competency Framework & 1 & 21 & 135 & 525 & 600 & 1282 & 4.33 \\
\hline 2. I am familiar with the pervasive skills as detailed in SAICA's Competency Framework & 4 & 22 & 160 & 527 & 563 & 1276 & 4.27 \\
\hline 3. I developed the necessary pervasive skills in preparation for the APC & 10 & 38 & 200 & 606 & 426 & 1280 & 4.09 \\
\hline
\end{tabular}

$n$, number of participants who answered the question; $M$, mean; SAICA, South African Institute of Chartered Accountants; APC, Assessment of Professional Competence.

TABLE 2: Comparative results of aspirant chartered accountants' views on the new qualifying examination.

\begin{tabular}{lcccc}
\hline Comparative views on new qualifying examination & $\begin{array}{c}\text { Large firm } \\
(\boldsymbol{M})\end{array}$ & $\begin{array}{c}\text { Medium firm } \\
(\boldsymbol{M})\end{array}$ & $\begin{array}{c}\text { Small firm } \\
(\boldsymbol{M})\end{array}$ & $\begin{array}{c}\text { Public sector } \\
(\boldsymbol{M})\end{array}$ \\
\hline 1. I am familiar with the content of SAICA's Competency Framework & 4.28 & 4.30 & 4.39 & 4.49 \\
andustry & $\begin{array}{c}\text { Average } \\
(\boldsymbol{M})\end{array}$ & 4.48 & 4.33 & $0.009 *$ \\
2. I am familiar with the pervasive skills as detailed in SAICA's Competency Framework & 4.21 & 4.28 & 4.24 & 4.44 \\
3. I developed the necessary pervasive skills in preparation for the APC & 4.06 & 4.09 & 4.21 & 4.18 \\
\hline
\end{tabular}

$M$, mean; SAICA, South African Institute of Chartered Accountants; APC, Assessment of Professional Competence.

*Significant at $p \leq 0.05$ 
are presented in Table 3, from the most effective to the least effective, based on the mean.

From the results above, it is apparent that aspirant CAs are of the opinion that a combination of the academic and training programmes most effectively results in the development of pervasive skills (mean $=2.14$ ), followed by the training programme $($ mean $=2.31)$ and lastly the academic programme (mean $=2.89)$. This view is consistent with the findings of Strauss-Keevy (2014) from the perspective of academic providers. However, this is in contrast with the expectations of SAICA $(2016 \mathrm{~b} ; 2017 \mathrm{~b})$ and the accounting profession at large.

Several participants further clarified why the academic programme was ranked in last position:

'I feel that at a university, it is $100 \%$ academically orientated and based on the technical knowledge and not many pervasive skills are gathered during this period.' (Participant 34, large firm)

'I found that when the university concentrate on technical skills, and the training programme on pervasive skills, the combination is quite effective.' (Participant 385, large firm)

'In university, pervasive skills should be addressed more appropriately.' (Participant 112, large firm)

One of the participants remarked about the effectiveness of the training programme:

'The training programme prepared me appropriately for the APC examination on the pervasive skills required. The skills obtained during the traineeship at the client also assisted me in the APC exam.' (Participant 87, large firm)

However, not all the aspirant CAs accepted these views, as one participant remarked:

'I believe that the biggest drive of development of pervasive skills should be self-development, but with the encouragement and resources of SAICA and training firms.' (Participant 30, medium firm)

and another two participants felt that the training programme lacked pervasive skills development:
'More focus on pervasive skills in training programmes.' (Participant 44, small firm)

'More lecture and training schedules during the training programme.' (Participant 74, commerce and industry)

\section{Inferential statistics on aspirant chartered accountants' views on the vehicles that develop pervasive skills}

Further analysis of the data in Table 3 was conducted using one-way ANOVA test (Pallant 2011) to establish the significant variances within the aspirant CA group (see Table 4).

A noteworthy finding from the results of Table 4 indicates a significant difference among the training programmes en route to qualifying as a CA, with a $p$-value of less than 0.05 . Using the post hoc processing from the ANOVA test through robust tests of the equality of means, aspirant CAs from small firms rank the training programmes as the least effective vehicle for developing pervasive skills, whereas aspirant CAs from commerce and industry rank it as the highest and most effective vehicle for developing pervasive skills.

\section{Aspirant chartered accountants' views on additional vehicles that develop pervasive skills}

As part of Section 2 of the questionnaire, the aspirant CAs were asked the following question: 'which other vehicles result in the development of pervasive skills for aspirant CAs?' In this open-ended question, several participants mentioned case studies as detailed below:

'Giving voluntary case studies and solutions to practice on in your own time.' (Participant 14, large firm)

'Case study-based courses at university.' (Participant 56, large firm) 'It would be wonderful if case studies were used from early on so that the application of knowledge is developed at early stages.' (Participant 490, large firm)

'Possible interaction with other audit firms, for example, case studies monitored by SAICA for different trainees to interact.' (Participant 358, medium firm)

'More contact with typical language subject activities, writing academic reports, summaries, essays, case studies, etc.' (Participant 229, large firm)

'Real-world application case studies at university.' (Participant 179 , large firm)

TABLE 3: Aspirant chartered accountants' views on the vehicles that most effectively develop pervasive skills.

\begin{tabular}{|c|c|c|c|c|c|c|}
\hline Views on the vehicles that develop pervasive skills & 1 & 2 & 3 & 4 & $n$ & $M$ \\
\hline Combination of the academic and training programmes & 250 & 148 & 124 & 106 & 628 & 2.14 \\
\hline Training programmes en route to qualifying as a $\mathrm{CA}(\mathrm{SA})$ & 166 & 198 & 167 & 96 & 627 & 2.31 \\
\hline Professional programme in preparation of the APC & 107 & 154 & 205 & 162 & 628 & 2.67 \\
\hline University academic programmes en route to qualifying as a $\mathrm{CA}(\mathrm{SA})$ & 104 & 128 & 130 & 265 & 627 & 2.89 \\
\hline
\end{tabular}

University academic programmes en route to qualifying as a $C A(S A)$

627

$n$, number of participants who answered the question; $M$, mean; CA, chartered accountant; SA, South Africa; APC, Assessment of Professional Competence.

TABLE 4: Comparative results of aspirant chartered accountants' views on the vehicles that most effectively develop pervasive skills.

\begin{tabular}{|c|c|c|c|c|c|c|c|}
\hline Comparative views on the vehicles that develop pervasive skills & $\begin{array}{l}\text { Large firm } \\
\quad(M)\end{array}$ & $\underset{(M)}{\text { Medium firm }}$ & $\begin{array}{l}\text { Small firm } \\
(M)\end{array}$ & $\begin{array}{l}\text { Public sector } \\
(M)\end{array}$ & $\begin{array}{c}\text { Commerce } \\
\text { and industry } \\
(M)\end{array}$ & $\begin{array}{l}\text { Average } \\
(M)\end{array}$ & $p$ \\
\hline University academic programmes en route to qualifying as a $\mathrm{CA}(\mathrm{SA})$ & 2.77 & 2.91 & 3.11 & 3.02 & 3.11 & 2.89 & 0.080 \\
\hline Training programmes en route to qualifying as a $\mathrm{CA}(\mathrm{SA})$ & 2.33 & 2.38 & 2.52 & 2.09 & 1.96 & 2.31 & $0.013 *$ \\
\hline Professional programme in preparation for the APC & 2.77 & 2.63 & 2.50 & 2.44 & 2.70 & 2.67 & 0.133 \\
\hline Combination of the academic, professional and training programmes & 2.15 & 2.09 & 1.88 & 2.45 & 2.20 & 2.14 & 0.093 \\
\hline
\end{tabular}

$M$, mean; CA, chartered accountant; SA, South Africa; APC, Assessment of Professional Competence.

*Significant at $p \leq 0.05$ 
From the comments above, it is apparent that both the academic and the training programmes should use case studies to develop pervasive skills. Similarly, De Villiers and Fouché (2015) found that case studies could enhance pervasive skills and Keevy (2016a) observed that each SAICA pervasive skill could be developed and assessed by using case studies as a teaching tool.

The participants also mentioned that during the academic programme they should have the opportunity to do vacation work by applying their academic knowledge to the workplace. This is evident in the following comments:

'Practical experience during the studying portion of the programme would provide students with some real-world understanding and practical application of the theory.' (Participant 4, large firm)

'Holiday work during your university education programme.' (Participant 118, commerce and industry)

'Making vacation work compulsory to ensure that students obtain practical experience during studies.' (Participant 200, large firm)

'Vacation work during university holidays (being exposed to a professional environment early).' (Participant 368, public sector; Participant 278, large firm)

'Internships while studying.' (Participant 321, commerce and industry)

Mohamed and Lashine (2003) also agree that accounting academics should make more use of case studies to simulate real-life problems and have internship programmes to apply technical content to the workplace. However, Albrecht and Sack (2000:53) conveyed that 'not enough out-of-classroom experiences, service-learning assignments and shadowing of professionals' are used by academics, and that accounting academics are reluctant to use creative types of learning such as real companies and case analyses. Wells et al. (2009:18) attest to this by identifying that universities need to improve their curricula by offering a work learning experience that is more real and that there is 'an important balance between university and workplace environments' in preparing and developing pervasive skills.

The following participants advocated the use of mentorship programmes to assist with the development of pervasive skills:

'Development areas of candidates should be identified and this should be incorporated into the training with the assistance of mentors to offer direction to the candidates. I have noticed that most of us do not know our weaknesses and it makes it very difficult to identify areas lacking and of improvement.' (Participant 210, public sector)

'More practical mentoring.' (Participant 522, large firm; Participants 52, 113, small firms)
'Mentorship programmes.' (Participants 132, 339, 353, large firms; Participants 369, 387, 468, 470, medium firms; and Participant 297 , commerce and industry)

'Well-run mentorship programmes at training offices. In my personal experience there are mentorship programmes but they are not well run (i.e. mentor and mentee will have nothing in common).' (Participant 271, large firm)

The respondents made no mention of whether mentorship programmes should be implemented during the academic programme as only the training programme was mentioned in their comments. However, Keevy (2016b) found that all SAICA's pervasive skills could be developed by using mentorship programmes during qualification. Furthermore, several studies found mentorship programmes to be beneficial during a university setting as well as in the work environment (Benjamin et al. 2007; Flemming 1996; IFAC 2015; Zachary 2002). Therefore, this vehicle could be applied during both programmes.

Lastly, the respondents mentioned that being seconded to different work environments was an additional resource for pervasive skills development en route to qualification:

'Secondments within audit firms (to gain experience on other industries not offered by one's respective firm).' (Participant 89 , large firm)

'Exchange programmes between commerce and auditing firms gains you exposure to different management styles and skills needed in a different environment.' (Participant 76, public sector)

\section{Aspirant chartered accountants' views on separate courses to develop the pervasive skills}

The objective in the last section of the questionnaire, as set out in Table 5, was to ascertain if the aspirant CAs thought that separate courses should be offered during the academic and the training programmes to aid in the development of pervasive skills. A five-point Likert scale was used to rate the statements presented below: 1 = don't agree at all; 2 = agree to a lesser extent; 3 = agree to a moderate extent; $4=$ agree to a large extent; 5 = agree completely.

The majority of the aspirant CAs view that both the academic and the training programmes should have separate courses or modules to develop pervasive skills; $33 \%$ and $32 \%$ of the aspirant CAs, respectively, 'agreed completely' with these two statements. Furthermore, $23 \%$ and $28 \%$ of the aspirant CAs, respectively, 'agreed to a large extent' that the academic and the training programmes should have separate courses or modules.

One of the participants shed further light on the above results by remarking:

TABLE 5: Aspirant chartered accountants' views on separate courses to develop pervasive skills.

\begin{tabular}{|c|c|c|c|c|c|c|c|}
\hline Views on separate courses to develop pervasive skills & 1 & 2 & 3 & 4 & 5 & $n$ & $M$ \\
\hline 1. Academic programmes should have separate courses or modules to develop pervasive skills & 59 & 83 & 137 & 143 & 210 & 632 & 3.57 \\
\hline 2. Training programmes should have separate courses or modules to develop pervasive skills & 48 & 86 & 120 & 174 & 204 & 632 & 3.63 \\
\hline
\end{tabular}

$N$, number of participants who answered the question; $M$, mean. 
'I believe that universities should have programs to enhance pervasive skills, yet training programmes should bare the bulk of the load. The training programmes encompass on the job learning and would be most effective in assisting trainees develop pervasive skills.' (Participant 387, medium firm)

This view was shared by another participant who stated that: 'More lectures should be provided during the 3-year training programme to develop pervasive skills.' (Participant 74, commerce and industry)

One participant added to this by saying:

'If a separate course is to be provided at University, it should be done at an undergraduate level.' (Participant 77, large firm)

All the aspirant CAs did not universally accept this view, as one participant commented that:

'Pervasive skills should not be treated as separate courses, they are inherent in the way we conduct ourselves in the business, when interacting with other individuals within the organisation/ institution and how we respond to change and the challenges we face whether it be at training or in university. At all times trainees or students must be encouraged to think holistically about the particular tasks they are doing, or problems they encounter along the way and understand the role of each subject area (be it tax, accounting, auditing, finance, strategy, governance, etc.).' (Participant 331, public sector)

Furthermore, several participants felt that pervasive skills should merely form part of the current programmes:

'I believe that separate modules are not required, as the pervasive skills should rather be taught in conjunction with the course material (in universities) and the pervasive skills are mostly developed on the job (as part of training programmes).' (Participant 459, large firm)

'I don't believe that the universities or training programmes should have separate programmes, but these types of learning should be incorporated into the already existing learning channels.' (Participant 382, large firm)

'I think universities can incorporate pervasive skills into all their subjects as opposed to it being a separate course. It can be a part of what is traditionally known as "exam technique".'

'I feel like the pervasive skills should just be highlighted more in certain university courses. For example the lecturers should take us through the decision making process and management had to use the various different skills at different times.' (Participant 80, large firm)

Certain participants remarked that pervasive skills cannot be taught:

'Cannot force these skills, they have to be developed by learning in the workplace and from peers/managers/team members.' (Participant 127, commerce and industry)
'Professional skills can't really be taught, especially in the work environment, you learn from those around you, and the training programme is designed to assess your developmental needs.' (Participant 157, medium firm)

'Training programmes develop these pervasive skills inherently through culture and on the job experience.' (Participant 168, large firm)

Several participants felt that both programmes were already too onerous:

'University and training programmes are already very full. To add to this workload will push incoming candidates past the breaking point.' (Participant 479, large firm)

'Universities should not cover this because the load in university is already significant enough and it's a well-structured process. Gain technical knowledge through university then develop skills through training. If universities incorporate this, training period might as well be reduced.' (Participant 166, large firm)

'There is a lot of material to cover at University, a separate course is not necessary but inclusion into the compulsory courses might be useful. The best place to learn practically is during the training programme.' (Participant 349, commerce and industry)

'If a separate course for pervasive skills is implemented then the workload on all the other subjects must be reconsidered, I struggled with the volume of work in honours and undergraduate.' (Participant 462, large firm)

Given the comments above, De Villiers (2010) concurs that pervasive skills should be embedded into the programmes at all levels instead of providing special pervasive skills training in stand-alone courses.

\section{Inferential statistics on aspirant chartered accountants' views on separate courses to develop the pervasive skills}

Further analysis of the data in Table 5 was conducted by means of the one-way ANOVA test as well as post hoc processing to establish the significant variances within the aspirant CA group (see Table 6).

Results from the analysis indicate that there is a statistical significance with the findings on whether training programmes should develop separate courses to develop pervasive skills $(p=0.00)$. Aspirant CAs at small and medium firms and from the public sector indicated a preference for separate courses or modules to assist them in developing pervasive skills, more so than their counterparts from large firms and commerce and industry.

\section{Conclusion, limitations and areas for further research}

The aim of this article was to ascertain the perceptions of aspirant CAs on the effectiveness of the transfer of pervasive

TABLE 6: Comparative results on aspirant chartered accountants' views on separate courses to develop pervasive skills.

\begin{tabular}{|c|c|c|c|c|c|c|c|}
\hline Comparative views on separate courses to develop pervasive skills & $\begin{array}{c}\text { Large } \\
\text { firm }(M)\end{array}$ & $\begin{array}{l}\text { Medium } \\
\text { firm }(M)\end{array}$ & $\begin{array}{l}\text { Small firm } \\
(M)\end{array}$ & $\begin{array}{c}\text { Public } \\
\text { sector }(M)\end{array}$ & $\begin{array}{c}\text { Commerce } \\
\text { and industry } \\
(M)\end{array}$ & $\begin{array}{c}\text { Average } \\
(M)\end{array}$ & $p$ \\
\hline Academic programmes should have separate courses or modules to develop pervasive skills & 3.45 & 3.73 & 3.59 & 3.91 & 3.41 & 3.57 & 0.55 \\
\hline Training programmes should have separate courses or modules to develop pervasive skills & 3.46 & 3.91 & 3.80 & 4.02 & 3.19 & 3.63 & $0.00 *$ \\
\hline
\end{tabular}


skills by means of the academic and the training programmes en route to qualifying as a CA. The findings indicated that candidates were of the viewpoint that pervasive skills were developed en route to qualifying. However, an interesting shortfall of the CA profession identified in the commentary was that candidates were not equipped with entrepreneurial skills. For example, business acumen, innovation, creativity and business start-up skills. Therefore, this could be an area of focus for SAICA going forward.

It was evident that the aspirant CAs view that a combination of the academic and training programmes most effectively develops the pervasive skills. This was similarly suggested in the literature (Ballantine \& McCourt Larres 2009; Bui \& Porter 2010; IFAC 2015). However, corresponding to what was suggested by various researchers (De Villiers 2010; Jackling \& DeLange 2009; Lines \& Gammie 2004; Strauss-Keevy 2014), the training programme plays a bigger role in skills development compared to the academic programme. A noteworthy comment from an aspirant CA affirmed this view:

'I feel that at a university, it is $100 \%$ academically orientated and based on the technical knowledge and not many pervasive skills are gathered during this period.' (Participant 34, medium firm)

As academics still have a long way to go in terms of the delivery of pervasive skills, there is potential for academics at different institutions to collaborate on how they are equipping graduates with these skills. It was recommended that during the training programme, candidates should be seconded to different work environments. Therefore, training officers should more readily create exchange programmes for trainees to gain 'exposure to different management styles and skills needed in different environments', thereby also aiding pervasive skills development.

The empirical evidence to the question as to whether the academic and the training programmes should have separate modules to develop the pervasive skills revealed that candidates were inclined to want separate modules. However, it was declared that the qualification route is already loaded, for example, 'University and training programmes are already very full. To add to this work load will push incoming candidates past the breaking point'. Nevertheless, a suggestion was made that pervasive skills should be embedded into the curriculum, as was also recommended by De Villiers (2010).

This study also revealed that aspirant CAs see the benefit of 'out of classroom experiences' (Albrecht \& Sack 2000) such as having case studies, mentorship programmes and getting practical experience through internships, which are all methods that could assist in embedding pervasive skills into the qualification model. Academics could approach businesses for assistance in the development of case studies to simulate the business environment and similarly create partnerships with businesses to mentor graduates.

The comparative results for candidates from different training programmes indicated that candidates from small firms view the training programme as the least effective vehicle in developing pervasive skills, whereas commerce and industry candidates view it as the most effective. In addition, candidates from small and medium firms and the public sector indicated that the training programme should have separate courses to develop pervasive skills, more so than their counterparts from large firms and commerce and industry. Therefore, there is potential for these training environments to work on their pervasive skill delivery.

Certain limitations to this study may implicate the interpreting of the results. For instance:

- The questionnaire may not have given aspirant CAs an opportunity to express their perceptions fully.

- The data were collected from aspirant CAs qualifying in South Africa. Therefore, the generalisability of the results could be limited because the questionnaire was specifically associated with the academic and the training programmes in South Africa.

- The study did not measure the actual benefit of the academic and the training programmes, but merely where the aspirant CAs viewed that pervasive skills were most effectively developed en route to qualifying.

Future research could build on the findings of this study by addressing how pervasive skills can be better implemented in the current qualification model, by investigating the impact of using different methods such as case studies, internships and mentorship programmes during the academic and the training programmes. Despite the limitations detailed above, aspirant CAs views that both the academic and the training programmes have a role to play in developing pervasive skills and that both programmes are critical to the success in qualifying as a CA. However, both programmes have scope to continually strengthen and revisit their programmes in light of the continual changes in the business environment.

\section{Acknowledgements}

The authors thank the South African Institute of Chartered Accountants for supporting this research and assisting in providing the email addresses of aspirant chartered accountants after writing the Assessment of Professional Competence.

\section{Competing interests}

The authors declare that they have no financial or personal relationships which may have inappropriately influenced them in writing this article.

\section{Authors' contributions}

Both authors equally contributed to the research and writing of this article.

\section{References}

Adler, R.W. \& Milne, M.J., 1997, 'Improving the quality of accounting students' learning through action-orientated learning tasks', Accounting Education 6(3), 191-215. https://doi.org/10.1080/096392897331442

Albrecht, W. \& Sack, R., 2000, Accounting education: Charting the course through a perilous future, Accounting Education Series, American Accounting Association,
Sarasota, FL. 
Atkins, M.J., 1999, 'Oven ready and self-basting: Taking stock of employability skills', Teaching in Higher Education 4(2), 267-280. https://doi.org/10.1080/135625 Teaching in
1990040208

Ballantine, J. \& McCourt Larres, P., 2009, 'Accounting undergraduates' perceptions of cooperative learning as a model for enhancing interpersonal and communication skills to interface successfully with professional accountancy education and training', Accounting Education: An International Journal 16(4), 387-402. https:// training, Accounting Education: An Intern
doi.org/10.1080/09639280902719366

Bampton, R. \& Cowton, C.J., 2002, 'Pioneering in ethics teaching: The case of management accounting', Teaching Business Ethics 2, 279-295. https://doi.org/ 10.1023/A:1016143911361

Barac, K., 2009, 'South African training officers' perceptions of the knowledge and skills requirements of entry-level trainee accountants', Meditari Accountancy Research 17(2), 19-46. https://doi.org/10.1108/10222529200900010

Barac, K. \& Du Plessis, L., 2014, 'Teaching pervasive skills to South African accounting students', South African Business Review 18(1), 53-79.

Benjamin, L.Z., Schlosser, L.Z., Sedlacek, W.E. \& Sheu, H., 2007, 'Mentoring in academia: Considerations for diverse populations', in T.D. Allen \& L.T. Eby (eds.), The Blackwell handbook of mentoring: A multiple perspectives approach, Blackwell Publishing Ltd.

Bui, B. \& Porter, B., 2010, 'The expectation-performance gap in education accounting: An exploratory study', Accounting Education: An International Journal 19(1), An exploratory study', Accounting Education: An Inte

Crebert, G., Bates, M., Bell, B., Patrick, C. \& Cragnolini, V., 2004, Developing generic skills at university, during work placement and in employment: Graduates perceptions, viewed 13 March 2018, from https://researchrepository.griffith.edu. perceptions, viewed 13 March 2018, from https://researchrep
au/bitstream/handle/10072/5454/26049_1.pdf?sequence $=1$

De Lange, P., Jackling, B. \& Gut, A., 2006, 'Accounting graduates' perceptions of the skills emphasis in undergraduate courses: An investigation from two Victorian universities', Accounting and Finance 46, 365-386. https://doi.org/10.1111/ j.1467-629X.2006.00173.x

De Villiers, R., 2010, 'The incorporation of soft skills into accounting curricula: Preparing accounting graduates for their unpredictable futures', Meditari Accountancy Research 18(2), 1-22. https://doi.org/10.1108/10222529201000007

De Villiers, R.R. \& Fouché, J.P., 2015, 'The effectiveness of the teaching methodologies in audit education: A student perspective', South African Journal of Higher Education 29(6), 55-77.

Flemming, A.I.M., 1996, 'Ethics and accounting education in the UK - A professional approach?', Accounting Education 5(3), 207-217. https://doi.org/10.1080/0963 9289600000021

Fouché, J.P. \& Visser, S.S., 2008, 'An evaluation of the integration of a board game in introductory accounting', South African Journal of Higher Education 22(3), 588-601.

Frank, G., Gradisher, S. \& Ofobike, E., 2010, 'Teaching business ethics: A quandary for accounting educators', Journal of Education for Business 85, 132-138. https://doi. accounting educators', Journal of Educ
org/10.1080/08832320903252413

Gammie, B., Gammie, E. \& Cargill, E., 2002, 'Personal skills development in the accounting curriculum', Accounting Education 11(1), 63-78. https://doi.org/ 10.1080/09639280210153272

Gammie, E., Cargill, E. \& Hamilton, S., 2010, Searching for good practice in the development and assessment of non-technical skills in accountancy trainees $-A$ global study, The Robert Gordon University, Aberdeen, Scotland.

Hesketh, J.H., 2011, 'Accounting academics' multiple challenges: Issue-driven learning offers a way forward', SA Journal of Accounting Research 25(1), 1-34. https://doi. org/10.1080/10291954.2011.11435151

International Federation of Accountants (IFAC), 2006, Approaches to the development and maintenance of professional values, ethics and attitudes in accounting education programmes, viewed 29 September 2011, from http://www. accountingweb-cgi.com/whitepapers/approaches_to.pdf

International Federation of Accountants (IFAC), 2015, Handbook of International Education Pronouncements, viewed 20 October 2016, from http://www.ifac.org/ system/files/publications/files/IAESB-2015-Handbook_0.pdf

Jackling, B., Cooper, B.J., Leung, P. \& Dellaportas, S., 2007, 'Professional accounting bodies' perceptions of ethical issues, causes of ethical failure and ethics education', Managerial Auditing Journal 22(9), 924-944. https://doi.org/10.1108/ education', Manageria

Jackling, B. \& De Lange, P., 2009, 'Do accounting graduates' skills meet the expectations of employers? A matter of convergence or divergence', Accounting Education: An International Journal 18(4-5), 369-385. https://doi.org/10.1080/0963928090 2719341

Kavanagh, M.H. \& Drennan, L., 2008, 'What skills and attributes does an accounting graduate need? Evidence from student perceptions and employer expectations', Accounting and Finance 348, 279-300. https://doi.org/10.1111/j.1467-629X 2007.00245.x

Keevy, M., 2015, 'Using collaborative learning exercises to transfer pervasive skills: Some South African Evidence', Journal of Economic and Financial Sciences 8(2) 456-473.
Keevy, M., 2016a, 'Using case studies to transfer soft skills (also known as pervasive skills): Empirical evidence', Meditari Accountancy Research 24(3), 458-474. https://doi.org/10.1108/MEDAR-04-2015-0021

Keevy, M., 2016b, 'Using mentorship programmes to transfer pervasive skills (soft skills): Empirical evidence', in GAl International Academic Conferences Proceedings, pp. 42-54, viewed 22 August 2017, from https://www.globalacademicinstitute. com/wp-content/uploads/2016-prague-conference-proceedings.pdf\#page=48

Kermis, G. \& Kermis, M., 2010, 'Professional presence and soft skills: A role for accounting education', Journal of Instructional Pedagogies 2, 1-10.

Lines, D. \& Gammie, E., 2004, Assessment methods report to the education committee of the International Federation of Accountants, The Robert Gordon University, Aberdeen, Scotland.

Low, M., Samkin, G. \& Liu, C., 2013, 'Accounting education and the provision of soft skills: Implications of the recent NZICA CA academic requirement changes', e-Journal of Business Education and Scholarship of Teaching 7(1), 1-33.

Mohamed, E.K.A. \& Lashine, S.H., 2003, 'Accounting knowledge and skills and the challenges of a global business environment', Managerial Finance 29(7), 3-6. https://doi.org/10.1108/03074350310768319

Pallant, J., 2011, SPSS survival manual: A step by step guide to data analysis using SPSS, 4th edn., Allen \& Unwin, NSW.

Smith, M.L., 2003, 'A fresh look at accounting ethics (or DR Smith goes to Washington)', Accounting Horizons 17(1), 47-69. https://doi.org/10.2308/acch.2003.17.1.47

South African Institute of Chartered Accountants (SAICA), 2009, Competency framework. Competencies of a chartered accountant (SA) at entry point to the profession, viewed 06 November 2015, from https://www.saica.co.za/LearnersStudents/ Examinations/Informationonwhatwillbeexamined/CompetencyFramework/ tabid/780/language/en-ZA/Default.aspx

South African Institute of Chartered Accountants (SAICA), 2013, Guidelines for the qualifying examination- Assessment of Professional Competence (APC), SAICA, Johannesburg.

South African Institute of Chartered Accountants (SAICA), 2015a, Overview of changes to Part /I exam, viewed 15 September 2015, from https://www.saica.co.za/ LearnersStudents/Examinations/ChangestoPartllexamAPC/Overview/tabid/2993/ language/en-ZA/Default.aspx

South African Institute of Chartered Accountants (SAICA), 2015b, Changes to part II exam 2014 APC, viewed 15 September 2015, from https://www.saica.co.za/ LearnersStudents/Examinations/ChangestoPartllexamAPC/ChangesToPartllExam 2014APC/tabid/2995/language/en-ZA/Default.aspx

South African Institute of Chartered Accountants (SAICA), 2016a, Accreditation and Monitoring Framework for Academic and Monitoring Programmes which satisfy the requirements for the qualification of chartered accountants, Professional Development Unit SAICA, Johannesburg.

South African Institute of Chartered Accountants (SAICA), 2016b, Competency framework detailed guidance for the Academic Programme Competencies of a CA(SA) at the point of the Initial Test of Competence (ITC) - Assessment of core technical knowledge, SAICA, Johannesburg.

South African Institute of Chartered Accountants (SAICA), 2017a, Examination setting, marking and adjudication policy for the initial test of competence (ITC), viewed 26 June 2017, from https://www.saica.co.za/Portals/0/LearnersStudents/Examinations/ SAICAs\%2OITC\%20Exam_setting_marking_and_adjudication_policy.pdf

South African Institute of Chartered Accountants (SAICA), 2017b, The goal of accounting education and training, viewed 22 August 2017, from https://www. saica.co.za/Training/Training/tabid/411/language/en-ZA/Default.aspx

South African Institute of Chartered Accountants (SAICA), 2017c, Training regulations, viewed 22 August 2017, from https://www.saica.co.za/Portals/0/Trainees/ documents $/ 1 \% 20$ January $\% 202017 \% 20$ Final\%20clean.pdf

Star, C. \& Hammer, S., 2008, 'Teaching generic skills: Eroding the higher purpose of universities, or an opportunity for renewal?', Oxford Review of Education 43(2), 237-251. https://doi.org/10.1080/03054980701672232

Steenkamp, G., 2012, 'Student perceptions regarding the new programme for chartered accountants', Journal of Economic and Financial Sciences 5(2), 485-502.

Strauss-Keevy, M., 2014, 'Education programmes' responsibilities regarding pervasive skills', Journal of Economic and Financial Sciences 7(2), 415-432.

Viviers, H.A., 2016, 'Qualitative evaluation of the design variables of a teaching intervention to expose accounting students to pervasive skills', Industry and Higher Education 30(6), 402-414. https://doi.org/10.1177/0950422216664244

Wells, P., Gerbric, P., Kranenburg, I. \& Bygrave, J., 2009, Professional skills and capabilities of accounting graduates: The New Zealand Expectation Gap? viewed 15 August 2017, from https://www.researchgate.net/publication/46529203 Professional_Skills_and_Capabilities_of_Accounting_Graduates_The_New_ Zealand_Expectation_Gap

Zachary, L.J., 2002, 'The role of teacher as mentor', New Direction for Adult and Continuing Education 93, 27-38. https://doi.org/10.1002/ace.47 